\title{
Overexpression, purification, molecular characterization and pharmacological evaluation for anticancer activity of ribosomal protein S23 from the giant panda (Ailuropoda melanoleuca)
}

\author{
TING WANG, YILING HOU, XIANG DING, BO SONG, FANG WANG and WANRU HOU \\ Key Laboratory of Southwest China Wildlife Resources Conservation (Ministry of Education), \\ College of Life Sciences, China West Normal University, Nanchong, Sichuan 637009, P.R. China
}

Received February 27, 2013; Accepted April 9, 2013

DOI: $10.3892 / \mathrm{mmr} .2013 .1430$

\begin{abstract}
Ribosomal protein S23 (RPS23) is a component of the 40S small ribosomal subunit encoded by the RPS 23 gene, which is specific to eukaryotes. The cDNA and genomic sequence of RPS23 were cloned from Ailuropoda melanoleuca (A.melanoleuca) using reverse transcription-polymerase chain reaction (RT-PCR) technology and touchdown PCR, respectively. The two sequences were analyzed preliminarily and the cDNA of the RPS23 gene was overexpressed in Escherichia coli (E. coli) BL21. The cDNA of RPS23 cloned from giant panda was $472 \mathrm{bp}$, and it contained an open reading frame (ORF) of 432 bp encoding 142 amino acids. The nucleotide sequence of the coding sequence showed a high degree of homology to some mammals as determined by BLAST analysis, similar to the amino acid sequence. The genomic sequence was 2,105 bp in length, with 4 exons and 3 introns. The primary structure analysis revealed that the molecular weight of the putative RPS23 protein was $15.80 \mathrm{kDa}$ with a theoretical isoelectric point (pI) of 11.23. The molecular weight of the recombinant protein RPS23 was $21.5 \mathrm{kDa}$ with a theoretical pI of 10.57. Topology prediction showed that there are seven different patterns of functional sites in the RPS23 protein of giant panda. RPS 23 was successfully expressed in $E$. coli and its protein fused with the N-terminal His-tagged protein triggered the accumulation of an expected $21.5-\mathrm{kDa}$ polypeptide. The inhibitory rate of tumor growth in mice treated with $0.1 \mu \mathrm{g} / \mathrm{ml} \mathrm{RPS} 23$ protein was $49.45 \%$, the highest in the three doses used, which may be comparable to mannatide treatment. Histology of immune organs showed that the tissues
\end{abstract}

Correspondence to: Dr Xiang Ding, Key Laboratory of Southwest China Wildlife Resources Conservation (Ministry of Education), College of Life Sciences, China West Normal University, 1 Shida Road, Nanchong, Sichuan 637009, P.R. China

E-mail: hwr@cwnu.edu.cn

Key words: giant panda, ribosomal protein S23, cDNA, cloning, overexpression, purification, anticancer activity were characterized by a regular and tight arrangement, while tumor tissues of the mice in the RPS23 group exhibited a loose arrangement compared to the control group. However, there was no obvious damage to other organs, such as the heart, lung and kidney. Investigations are currently being conducted to determine the bioactive principles of the recombinant protein RPS23 responsible for its anticancer activity.

\section{Introduction}

Ribosomes, the organelles that catalyze protein synthesis, consist of a small 40S subunit and a large 60S subunit each, and are the components of cells that produce proteins from all amino acids $(1,2)$. Ribosomal protein S23 (RPS23) gene encodes a ribosomal protein, as a component of the $40 \mathrm{~S}$ subunit. This protein belongs to the S12P family of ribosomal proteins, is located in the cytoplasm and is crucial in the development of human diseases. Multiple processed pseudogenes of this gene are dispersed throughout the genome, which is typical for genes encoding ribosomal proteins (3).

Ribosomal protein gene mutations or disturbance in their expression levels have been observed in a number of inherited genetic diseases such as Tuner syndrome, Diamond-Blackfan anemia syndrome, Camurati-Engelmann disease, Noonan syndrome, and Bardet-Biedl syndrome (4). The physiological function of ribosomal proteins in human diseases has been progressively clarified due to the progress in the scientific techniques as well as the continuous and in-depth research (4). $R P S 23$ gene is involved in cell growth and regulation. The small ribosomal protein RPS23 has been found to be located in the vicinity of the mRNA entry channel and to play an important role in identifying specific interactions of the human eukaryotic translation initiation factor (eIF) 3 (5). The eukaryotic translation initiation factor eIF5B is a ribosome-dependent GTPase that mediates the displacement of initiation factors from the $40 \mathrm{~S}$ ribosomal subunit, and RPS 23 has been shown to be located in its domain 2 (6). A mouse gene recently identified, RPS23 retroposed gene 1 (RPS23rgl), was found to regulate $\beta$-amyloid $(\mathrm{A} \beta$ ) levels and tau phosphorylation, two major pathological hallmarks of Alzheimer's disease (AD), and RPS23rgl was also found to originate through retroposition of the mouse RPS23 mRNA (7). 
Cancer is one of the leading causes of mortality worldwide and is medically known as a malignant neoplasm. This is a term for a large group of different diseases, all involving unregulated cell growth (8). Cancer cells divide rapidly, grow in an uncontrolled manner, form malignant tumors and invade neighbouring parts of the body. Cancer may also spread to more distant parts of the body through the lymphatic system or bloodstream (9). Cancer is one of the most fatal diseases in the human population and constitutes a common cause of death worldwide $(10,11)$. However, many proteins possess antitumor activities. The aim of the present study was to evaluate the anticancer activity of RPS23 protein from the giant panda.

Ailuropoda melanoleuca (A. melanoleuca), considered a National treasure of China, is one of the oldest species belonging to the group of endangered mammals. Macrograph of giant panda has been achieved. The investigation of gene function constitutes an important field in current giant panda research (12-17). The ribosomal protein RPS23 of the giant panda has received increasing attention due to its various biological functions, particularly in relation to anticancer activity.

In the present study, we used reverse transcription-polymerase chain reaction (RT-PCR) to amplify the cDNA of RPS23 gene from the total RNA of the skeleton muscle of giant panda, based on relative information regarding the RPS 23 gene of the designed primers of some mammals, including Homo sapiens (H. sapiens), Bos Taurus (B.Taurus), Felis catus (F.catus), Mus musculus (M. musculus) and Rattus norvegicus ( $R$. norvegicus). The sequence characteristics of the protein encoded by the cDNA was also analyzed and compared with those of human and other animals reported. A recombinant expression vector containing RPS23 cDNA was constructed and overexpressed in Escherichia coli (E. coli) using pET28a plasmids. Under the optimized expression conditions, many recombinant proteins of RPS23 were obtained from the giant panda, which were then purified using Ni chelate affinity chromatography. The aim of the present study was to evaluate the anticancer activity of RPS 23 protein from the giant panda in vivo.

\section{Materials and methods}

Materials. Skeletal muscle was collected from a dead giant panda provided from the Wolong Conservation Center of the Giant Panda (Sichuan, China). The collected skeletal muscle was frozen in liquid nitrogen and then used for RNA isolation. Total Tissue/Cell RNA Extraction kits were purchased from Waton Inc. (Shanghai, China). Reverse transcription kits were purchased from Promega, Beijing, China. Gel Extraction Mini kits were purchased from Omega (Kanpur, India). pMD19-T Vector Systems and the restriction enzymes EcoRI and HindIII were purchased from Takara Bio (Dalian, China). DNA polymerases were purchased from Sangon Co., Ltd. (Shanghai, China). Host bacteria E. coli DH5 $\alpha$ were stored in the Key Laboratory of Southwest China Wildlife Resources Conservation (Nanchong, China). CW0009 Ni-Agarose His-tag Protein purification kits were purchased from Beijing Ealysino Biological Technology Co., Ltd. (Beijing, China). Bradford Protein Assay kits were purchased from Majorbio
BioTech Co., Ltd. (Shanghai, China). Penicillin/streptomycin (penicillin 10,000 U/ml, streptomycin 10,000 $\mu \mathrm{g} / \mathrm{ml}$ ) and Dulbecco's modified Eagle's medium (DMEM) reagent were purchased from Gibco-BRL (Grand Island, NY, USA). Fetal bovine serum (FBS) was obtained from Sijiqing Biological Engineering Materials Co., Ltd. (Huangzhou, China).

DNA and RNA isolation. A total of $500 \mathrm{mg}$ of muscle tissue was ground in liquid nitrogen to a fine powder, and the powder was suspended completely in $15 \mathrm{ml}$ lysis buffer containing $10 \mathrm{mM}$ Tris-HCl, pH 8.0, $100 \mathrm{mM}$ EDTA and 0.5\% SDS. Following treatment with proteinase $\mathrm{K}$ (final concentration, $100 \mathrm{mg} / \mathrm{ml}$ ) at $55^{\circ} \mathrm{C}$ for $3 \mathrm{~h}$, the mixture was cooled to room temperature and mixed with an equal volume of saturated phenol ( $\mathrm{pH} 8.0)$ prior to centrifugation at $5,000 \mathrm{x} \mathrm{g}$ at $4^{\circ} \mathrm{C}$ for $20 \mathrm{~min}$. The supernatant was pooled and mixed with an equal volume of 1:1 (v:v) phenol-chloroform, followed by centrifugation as described above. The supernatant was then collected, from which the DNA was precipitated by ethanol. The DNA obtained was then dissolved in TE buffer and maintained at $-20^{\circ} \mathrm{C}$. Total RNAs were isolated from $\sim 400 \mathrm{mg}$ muscle tissue using the Total Tissue/Cell RNA Extraction kits (Waton Inc.) according to the manufacturer's instructions. The total RNAs extracted were dissolved in diethyl pyrocarbonate (DEPC) water and maintained at $-70^{\circ} \mathrm{C}$.

Primer design and RT-PCR. The PCR primers were designed using Primer Premier 5.0, according to the mRNA sequence of RPS23 gene from H. sapiens (NM_001025), B. Taurus (NM_001034690), M. musculus (NM_024175), S. scrofa (NM_213764) and $R$. norvegicus (NM_078617), as follows: RPS23 forward, 5'-AGGGAATTCATGGGTAAGTGTC-3' and reverse, 5'-ATTCTCGAGTTATGATCTTGGC-3'.

Total RNAs were synthesized into first-stranded cDNAs using a reverse transcription kit with oligo(dT) as the primers, according to the manufacturer's instructions (Promega, Madison, WI, USA). Twenty microliters of the first-strand cDNA synthesis reaction system were included in $1 \mathrm{mg}$ total RNAs, $5 \mathrm{mM} \mathrm{MgCl}_{2}, 1 \mathrm{mM}$ dNTPs, $0.5 \mathrm{mg}$ oligo(dT)15, $10 \mathrm{U} / \mathrm{ml}$ RNase inhibitor and 15 units of AMV reverse transcriptase, and incubated at $42^{\circ} \mathrm{C}$ for $60 \mathrm{~min}$. The first-strand cDNA synthesized was used as a template. The total reaction volume for DNA amplification was $25 \mu 1$. Reaction mixtures contained $1.5 \mathrm{mM} \mathrm{MgCl}, 200 \mu \mathrm{M}$ of each dATP, dGTP, dCTP and dTTP (Omega, China), $0.3 \mu \mathrm{M}$ of each primer, 5.0 units of Taq plus DNA polymerase (Sangon Co., Ltd.). DNA amplification was performed using an MJ Research PTC-200 Thermal Cycler (Watertown, MA, USA) with a program of $4 \mathrm{~min}$ at $94^{\circ} \mathrm{C}$, followed by 30 cycles of $1 \mathrm{~min}$ at $94^{\circ} \mathrm{C}, 0.5 \mathrm{~min}$ at $48^{\circ} \mathrm{C}$ and $1.5 \mathrm{~min}$ at $72^{\circ} \mathrm{C}$, with the final extension for $10 \mathrm{~min}$ at $72^{\circ} \mathrm{C}$. Following amplification, PCR products were separated by electrophoresis on $1.5 \%$ agarose gel with 1X TAE (Tris-acetate-EDTA) buffer, stained with ethidium bromide and visualized under ultraviolet (UV) light. The expected fragments of PCR products were harvested and purified from gel using a DNA harvesting kit (Omega) and stored at $-20^{\circ} \mathrm{C}$.

Cloning and identification of the cDNA sequence. The harvested PCR products were ligated into a pMD19-T vector 
at $4^{\circ} \mathrm{C}$ for $12 \mathrm{~h}$. The recombinant molecules were transformed into $E$. coli complete cells (DH5 $\alpha$ ), and then spread on the LB-plate containing $50 \mu \mathrm{g} / \mathrm{ml}$ ampicillin, $200 \mathrm{mg} / \mathrm{ml}$ isopropyl- $\beta$-D-thiogalactopyranoside (IPTG) and $20 \mathrm{mg} / \mathrm{ml}$ $\mathrm{X}$-gal. Plasmid DNA was isolated and digested by Pst I and ScaII to verify the insert size. Plasmid DNA was sequenced by Huada Zhongsheng Scientific Corporation (Beijing, China).

Cloning of the genomic sequence of RPS23. The PCR primers used were the RPS23 forward and reverse mentioned above. The genomic sequence of the RPS23 gene was amplified using touchdown PCR under the following conditions: $94^{\circ} \mathrm{C}$ for $30 \mathrm{sec}, 62^{\circ} \mathrm{C}$ for $45 \mathrm{sec}, 72^{\circ} \mathrm{C}$ for $4 \mathrm{~min}$ in the first cycle and the annealing temperature was decreased by $0.5^{\circ} \mathrm{C} /$ cycle; after 20 cycles, the conditions were changed to $94^{\circ} \mathrm{C}$ for $30 \mathrm{sec}$, $52^{\circ} \mathrm{C}$ for $45 \mathrm{sec}, 72^{\circ} \mathrm{C}$ for $4 \mathrm{~min}$ for an additional 20 cycles. The fragment amplified was also purified, ligated into the clone vector and transformed into $E$. coli competent cells. The recombinant fragment was then sequenced by Invitrogen (Carlsbad, CA, USA).

Construction of the expression vector and overexpression of recombinant RPS23. PCR fragment corresponding to the RPS23 polypeptide was amplified from the RPS23 cDNA clone with the forward, 5'-TGGAATTCATGGGTAAGTG TCG-3' (EcoRI) and reverse, 5'-TTAAGCTTTTATGA TCTTGGCC-3' (HindIII) primers, respectively. PCR was performed at $94^{\circ} \mathrm{C}$ for $3 \mathrm{~min} ; 35$ cycles of $30 \mathrm{sec}$ at $94^{\circ} \mathrm{C}$, $45 \mathrm{sec}$ at $53^{\circ} \mathrm{C}$ and $1 \mathrm{~min}$ at $72^{\circ} \mathrm{C} ; 10 \mathrm{~min}$ at $72^{\circ} \mathrm{C}$. The amplified PCR product was cut and ligated into the corresponding site of the pET28a vector (Stratagene, La Jolla, CA, USA). The resulting construct was transformed into the E. coli BL21 (DE3) strain (Novagen, Madison, WI, USA) and used for the induction by adding IPTG at an OD600 of 0.6 and culturing further for $4 \mathrm{~h}$ at $37^{\circ} \mathrm{C}$, using the empty vector-transformed BL21 (DE3) as a control. The recombinant protein samples were induced after $0,1,1.5,2,2.5,3$ and $4 \mathrm{~h}$, separated by SDS-PAGE and stained with Commassie Blue R-250.

Purification of recombinant protein RPS23. The acquired genetically modified recombinant protein has a tag comprising of six histidines (His-tag), thus Ni chelate affinity chromatography was conducted as described below. The ultrasonic product was centrifuged to collect sediments, which were then suspended with soluble binding buffer $(20 \mathrm{mM}$ Tris- $\mathrm{HCl}$, $0.5 \mathrm{M} \mathrm{NaCl}, 10 \mathrm{mM}$ imidazole, $\mathrm{pH}$ 7.9) until the inclusion body was clean. This was followed by centrifugation and suspension of the sediments with inclusion body binding buffer (20 mM Tris- $\mathrm{HCl}, 0.5 \mathrm{M} \mathrm{NaCl}, 5 \mathrm{mM}$ imidazole, urea $8 \mathrm{M}, \mathrm{pH}$ 7.9) on ice, until the inclusion body was thoroughly dissolved. The supernatant was centrifuged and transferred to the chromatography column with nickel. After the above supernatant was completely transferred, it was left to stand for 2 min so that the six His-tag and nickel in the padding were fully combined. Inclusion body binding buffer of 15 times the column volume was used to flush the column, in order to wash the uncombined protein. The excurrent liquid was collected. Subsequently, inclusion body elution buffer of 5 times the column volume was used to wash the combined protein. The outflow liquid was collected according to the amount of the column volume. SDS-PAGE was then used to detect the effect of purification. The concentration of recombinant protein was determined using Bradford Protein Assay kits. To purify the elution protein, dialysis was available. After $48 \mathrm{~h}$ of desalination, the purified protein with $10 \%$ glycerol was maintained at $-20^{\circ} \mathrm{C}$.

Animals. S180 tumor cells were maintained in the peritoneal cavities of male Kunming strain mice obtained from the Institute of Biochemistry and Molecular Immunology of North Sichuan Medical College (NSMC) (Nanchong, China). Male Kunming strain mice, weighing $25.0 \pm 1.0 \mathrm{~g}$, purchased from NSMC, were housed 6/plastic cage with wood chip bedding in an animal room with a 12-h light/dark cycle at room temperature $\left(25 \pm 2^{\circ} \mathrm{C}\right)$ and allowed free access to standard laboratory diet (purchased from the Institute of Biochemistry and Molecular Immunology, NSMC). The animal experiments were conducted according to the 'Guidelines for Animal Experimentation' of the NSMC.

Assessment of in vivo antitumor activity. S180 tumor cells $\left(3 \times 10^{6}\right)$ were implanted subcutaneously into the right hind groin of the male Kunming strain mice. The mice were randomly allocated into 5 groups ( $n=6 /$ group). One day after inoculation, RPS23 was dissolved in distilled water and administered intraperitoneally (i.p.) to mice at doses of $0.025,0.05$ and $0.1 \mu \mathrm{g} / \mathrm{ml}$ (S1, S2 and $\mathrm{S} 3$ groups, respectively). Positive and negative controls were set for comparison. Positive control mice (M group) were administered $0.2 \mathrm{ml}$ mannatide ( $2 \mathrm{mg} / \mathrm{ml}$ ) and negative control mice ( $\mathrm{N}$ group) were administered physiological saline instead of the test solution. The mice were sacrificed after 2 weeks and the body weights were measured. Tumors, spleens and livers were excised and the inhibitory ratio of tumor growth was calculated using the formula: Inhibition ratio $(\%)=[(\mathrm{A}-\mathrm{B}) / \mathrm{A}] \times 100$, where $\mathrm{A}$ and $\mathrm{B}$ were the average tumor weights of the negative control and treated groups, respectively.

Histopathological and morphological observations. After treating the mice with RPS23 as described above, a portion of the tissues were cut into small sections, fixed in Heidenhain's Susa Fluid $\left(\mathrm{HgCl}_{2}, 4.5 \mathrm{~g} ; \mathrm{NaCl}, 0.5 \mathrm{~g}\right.$; distilled water, $80.0 \mathrm{ml}$; formalin, $20.0 \mathrm{ml}$; acetic acid, $4.0 \mathrm{ml}$; trichloroacetic acid, $2.0 \mathrm{ml}$ ), stained with hematoxylin and eosin (H\&E), examined and photographed using an Olympus microscope.

Data analysis. Sequence data were analyzed by GenScan software (http://genes.mit.edu/GENSCAN.html). Homology investigations of the giant panda RPS 23 compared with the gene sequences of other species was performed using BLAST 2.1 (http://www.ncbi.nlm.nih.gov/blast/). Open reading frame (ORF) of the DNA sequence was searched using ORF Finder software (http://www.ncbi.nlm.nih.gov/gorf/gorf. html). Molecular weight (Mw) and isoelectric point ( $\mathrm{pI}$ ) values were computed using the Compute $\mathrm{pI} / \mathrm{Mw}$ tool (http://www. expasy.org/tools/pi_tool.html). The protein structure of the RPS23 sequence cloned was analyzed using PredictProtein software (http://cubic.bioc.columbia.edu/predictprotein/). Multiple Sequence Alignment was performed by DNASTAR Lasergene and DNAman 6.0 software. 
Table I. Comparison of nucleotide, amino acid sequences and physicochemical properties of RPS23 between A. melanoleuca and other five mammal species.

\begin{tabular}{|c|c|c|c|c|c|}
\hline \multicolumn{4}{|c|}{ Species } & \multirow[b]{2}{*}{ M. musculus } & \multirow[b]{2}{*}{ S. scrofa } \\
\hline Characteristics & H. sapiens & B.taurus & $R$. norvegicus & & \\
\hline CDS similarity (\%) & 92.59 & 92.82 & 88.66 & 88.43 & 93.29 \\
\hline aa similarity (\%) & 100 & 100 & 100 & 100 & 99.30 \\
\hline Molecular weight (kDa) & 15.80 & 15.80 & 15.80 & 15.80 & 15.81 \\
\hline $\mathrm{pI}$ & 11.23 & 11.23 & 11.23 & 11.23 & 11.23 \\
\hline
\end{tabular}

CDS, coding DNA sequence; aa, amino acid; pI, isoelectric point.

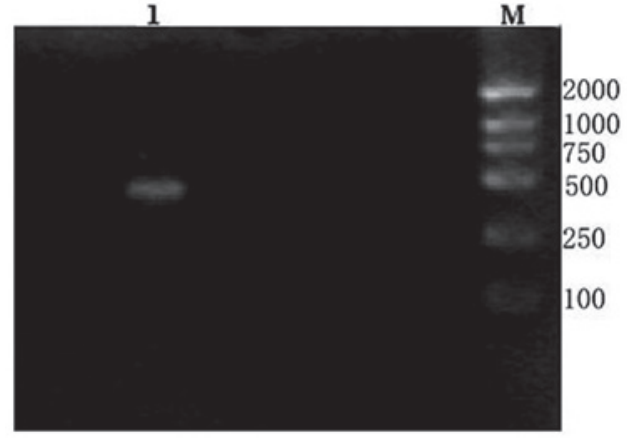

Figure 1. Reverse transcription-polymerase chain reaction (RT-PCR) products of the giant panda RPS23. Lane 1, amplified RPS23; lane M, molecular marker DL2000.

\section{Results and Discussion}

Analysis of RPS23 cDNA from the giant panda. Approximately $500 \mathrm{bp}$ of the cDNA fragment was amplified from the giant panda. The length of the cDNA cloned was 472 bp (Fig. 1). On the basis of the high identity, we concluded that the cDNA isolated is the cDNA encoding the giant panda RPS23 protein. The RPS23 sequence was submitted to GenBank (accession no. HQ318026). The 472 bp of the giant panda RPS23 sequence contains a 20-bp 5'-untranslated sequence and a 20-bp 3'-unstranslated region. An ORF of 432 bp encoding 142 amino acids was found in the cDNA sequence (Fig. 2). Alignment analysis of RPS23 from the giant panda and those of H. sapiens, M. musculus, $R$. norvegicus and M. mulatta, indicated that both the nucleotide and the deduced amino acid sequences are highly conserved. There was no deletion or insertion of nucleotide and amino acid residues. As determined by BLAST analysis, the nucleotide sequence RPS23 cloned from the giant panda shares a high degree of homology with those of $H$. sapiens, B. taurus, $R$. norvegicus, M. musculus and $S$. scrofa at 92.59, 92.82, 88.66, 88.43 and 93.29\%, respectively. The homologies for amino acid sequences were all $100 \%$, with the exception of S. scrofa, which was $99.30 \%$, compared with the remaining 6 species (Table I). This marked pattern of evolutionary conservation is considered reasonable, since ribosomal protein genes are a group of highly conserved housekeeping genes. The average levels of the base sequence was: A, 29.2; C, 20.6; G, 27.5; and T, 22.7\%.

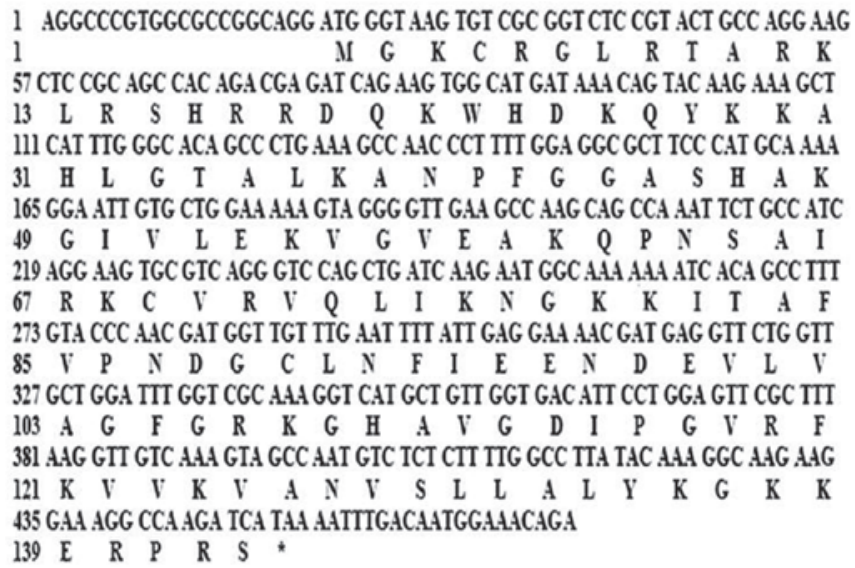

Figure 2. Nucleotide and putative amino acid sequence of RPS23 cDNA from A. melanoleuca. *Stop codon.

Analysis of the genomic sequence of RPS23 from the giant panda. A fragment of $2,000 \mathrm{bp}$ was amplified from the genonic DNA of the giant panda using RPS23 forward and reverse primers (Table II). The length of the DNA fragment cloned was 2,105 bp. Comparison between the cDNA sequence and this DNA fragment indicated that the cDNA sequence is a full cDNA corresponding to 4 exons in the RPS23 genomic sequence of the giant panda. The genomic sequence of the RPS23 gene has been submitted to GenBank (accession no. HQ_318027).

Prediction and analysis of protein functional sites in the RPS23 protein of the giant panda. The molecular weight of the putative RPS23 protein was $15.80 \mathrm{kDa}$ with a theoretical pI of 11.23, containing 37 positively charged (Arg, Lys and His), 11 negatively charged (Asp and Glu) and 95 uncharged amino acid residues. Among them, Lys was the optimum, and Trp was the least. Topology prediction showed there are 7 different patterns of functional sites: two N-myristoylation sites, one $\mathrm{N}$-glycosylation site, two protein kinase $\mathrm{C}$ phosphorylation sites, one cAMP- and cGMP-dependent protein kinase phosphorylation site, three amidation sites, one tyrosine kinase phosphorylation site and one ribosomal protein S12 signature site in the RPS23 protein of the A. melanoleuca. Comparison was conducted for functional sites of the RPS23 amino acid sequences among the different mammals, including $H$. sapiens, 
Table II. Comparison of RPS23 genomic sequences among 6 mammal species.

\begin{tabular}{lcccr}
\hline Species & Length $(\mathrm{bp})$ & No. of exons & Join sites in the CDS & Accession nos. \\
\hline A. melanoleuca & 2,105 & 4 & $21 . .24,499 . .658,1729 . .1849,1959 . .2105$ & HQ_318027 \\
H. sapiens & 5,097 & 4 & $94 . .97,565.724,1899 . .2019,2162 . .2308$ & NC_000005.9 \\
B. taurus & 1,860 & 4 & $32 . .35,487.646,1320 . .1440,1559 . .1705$ & NC_007305.4 \\
M. musculus & 1,611 & 4 & $75 . .78,466 . .625,1205 . .1325,1416 . .1562$ & NC_000079.5 \\
R. norvegicus & 1,571 & 4 & $40 . .43,447 . .606,1154 . .1274,1386 . .1532$ & NC_005101.2 \\
S. scrofa & 1,645 & 4 & $8 . .11,454 . .613,1257 . .1377,1494 . .1640$ & NC_010444.2
\end{tabular}

CDS, coding DNA sequence.

Table III. Antitumor activities of RPS23 on S180 tumors (mean \pm SD, n=6/group).

\begin{tabular}{|c|c|c|c|c|c|}
\hline Group & $\begin{array}{l}\text { Spleen index } \\
(\mathrm{mg} / \mathrm{g})\end{array}$ & $\begin{array}{l}\text { Liver index } \\
\quad(\mathrm{mg} / \mathrm{g})\end{array}$ & $\begin{array}{l}\text { Thymus index } \\
(\mathrm{mg} / \mathrm{g})\end{array}$ & $\begin{array}{l}\text { Average tumor weight } \\
(\mathrm{g})\end{array}$ & $\begin{array}{c}\text { Inhibitory rate of tumor } \\
\text { growth }(\%)\end{array}$ \\
\hline $\mathrm{N}$ & $5.74 \pm 2.18$ & $60.30 \pm 9.35$ & $1.32 \pm 0.71$ & $1.52 \pm 0.36$ & - \\
\hline S1 & $7.61 \pm 2.14$ & $55.46 \pm 4.50$ & $4.72 \pm 0.31$ & $1.00 \pm 0.74$ & $34.36^{\mathrm{a}}$ \\
\hline $\mathrm{S} 2$ & $7.87 \pm 3.27$ & $65.31 \pm 8.82$ & $7.71 \pm 3.23$ & $0.89 \pm 0.30$ & $41.32^{\mathrm{b}}$ \\
\hline $\mathrm{S} 3$ & $5.02 \pm 0.89$ & $57.54 \pm 4.76$ & $0.90 \pm 0.41$ & $0.77 \pm 0.28^{b}$ & $49.45^{b}$ \\
\hline M & $7.39 \pm 3.05$ & $56.23 \pm 5.39$ & $2.84 \pm 1.76$ & $0.29 \pm 0.14^{\mathrm{b}}$ & $81.03^{\mathrm{b}}$ \\
\hline
\end{tabular}

Significant differences from the negative control (N) and positive control (M) groups were evaluated using Student's t-test: ${ }^{a} \mathrm{P}<0.05$, ${ }^{b} \mathrm{P}<0.01$. $\mathrm{S} 1, \mathrm{~S} 2$ and S3 groups treated with $0.025,0.05$ and $0.1 \mu \mathrm{g} / \mathrm{ml} \mathrm{RPS} 23$, respectively.

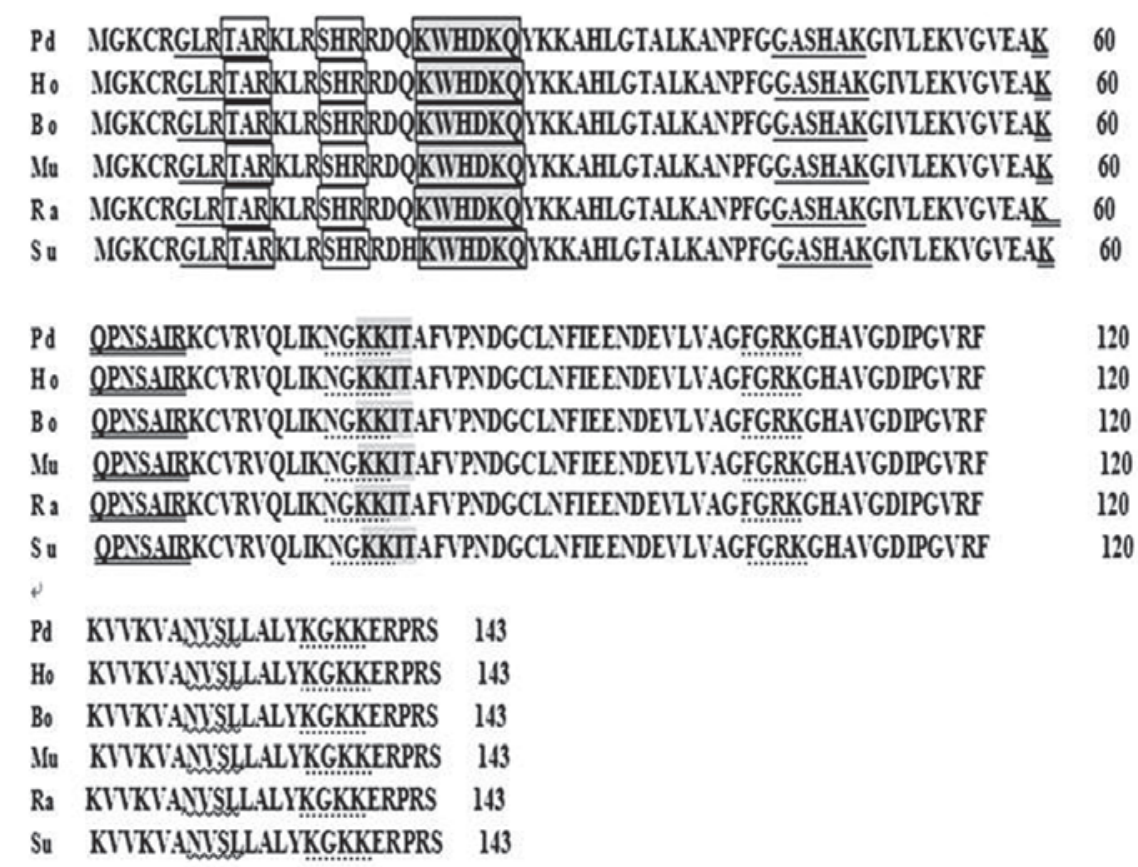

Figure 3. Comparison of the RPS23 amino acid sequences among the different species. Underlining: N-myristoylation site; open box, protein kinase C phosphorylation site; grey box with frame, tyrosine kinase phosphorylation site; grey box without frame, cAMP- and cGMP-dependent protein kinase phosphorylation site; dotted line, amidation site; double line, ribosomal protein s12 signature; wavy line, N-glycosylation site.

B. taurus, M. musculus, R. norvegicus and S. scrofa (Fig. 3). There was no deletion and insertion of nucleotide and amino acid residues observed. Further analysis indicated that there were polymorphic sites in these deduced amino acid sequences of RPS23 proteins. These polymorphic sites were located irregularly in the amino acid sequences all of which resulted 

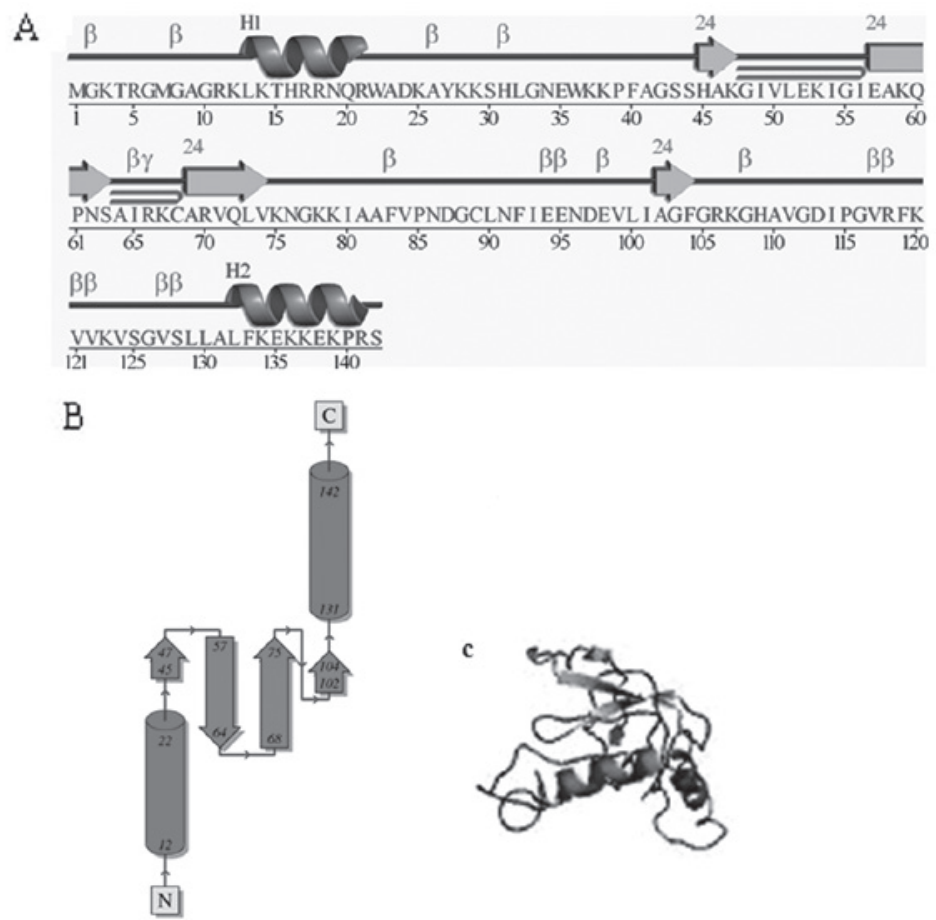

Figure 4. Secondary (A and B) and tertiary (C) structure of protein RPS23 from the giant panda. $\beta, \beta$ turn; H1 and H2, helixes; $\gamma, \gamma$ turn; $\Longrightarrow$ : $\beta$ hairpin; A, $\beta$ strands.

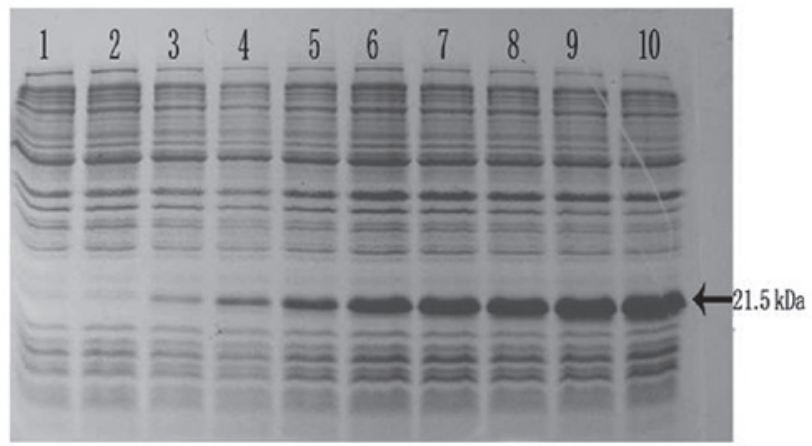

Figure 5. Protein extracted from recombinant E. coli BL21 strains was analyzed by SDS-PAGE gel stained with Commassie Blue R250. The number on the right indicates the molecular weight and the arrow indicates the recombinant protein bands induced by IPTG with $0,0.5,1,1.5,2,2.5,3,3.5$ and $4 \mathrm{~h}$ (lanes 2-10), respectively. Lane 1 represents the products of the E. coli strains with the empty vectors.

from the transversion or transition of the corresponding codons without any deletion and insertion of bases. Additionally, most base transitions of the gene coding sequence in these mammals were synonymous mutations. These synonymous mutations did not result in any changes in the corresponding DNA information and did not change the amino acid sequence of the expressed product. Consequently, the spatial structure of the corresponding protein was not affected.

Although some functional sites were not conserved since some polymorphic sites were located inside the functional sites, while others were located outside the functional sites, secondary and tertiary structure analysis showed that amino acid sequences formed the same main structures (Fig. 4). For

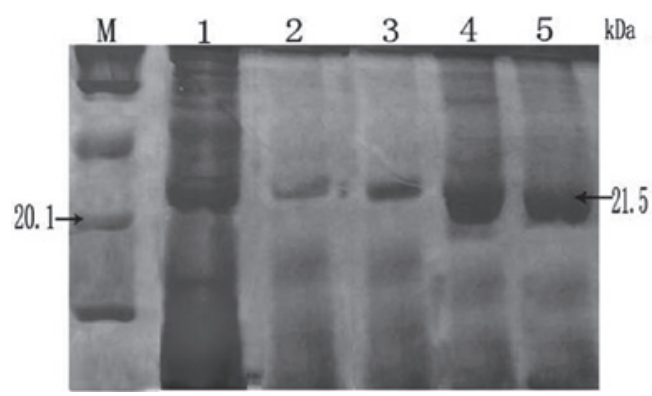

Figure 6. Purification of recombinant proteins RPS23. Lane 1, RPS23 proteins extracted from recombinant $E$. coli; lane 2, effluent liquid collected from columns; lanes 3-5, eluent collected from columns.

RPS23, residues spanned from 8 to 134 to form the same main structure: 3 helices $(8-15,25-31,129-134)$ and $5 \beta$ strands (49-59, 69-75, 80-85, 99-103, 119-125). These results show that the variation of sites has no effect on the structure and function of RPS23 protein. This finding may reflect previous evolutionary association between these proteins and the main, ancient structural and functional features of the ribosomal protein (RPS) family.

Overexpression and purification of the RPS23 gene in E. coli. The RPS23 gene was overexpressed in E. coli, using pET28a plasmids carrying strong promoter and terminator sequences derived from phage T7. For this purpose, the RPS23 gene was amplified individually using PCR and cloned in a pET28a plasmid, resulting in a gene fusion coding for a protein bearing a His-tag extension at the $\mathrm{N}$-terminal. Expression was assessed by SDS-PAGE analysis of protein extracts from recombinant in E. coli BL21 strains (Fig. 5). These results indicate that the 


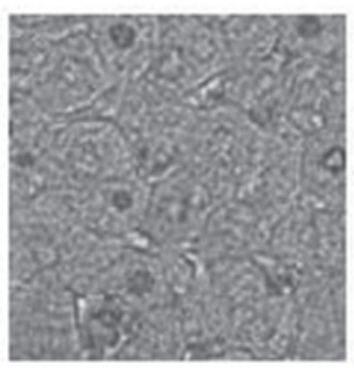

A

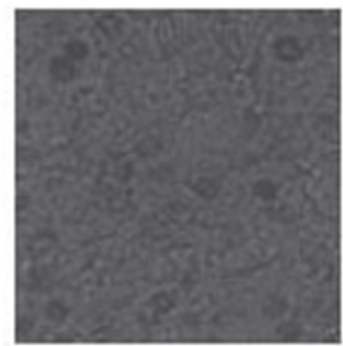

A

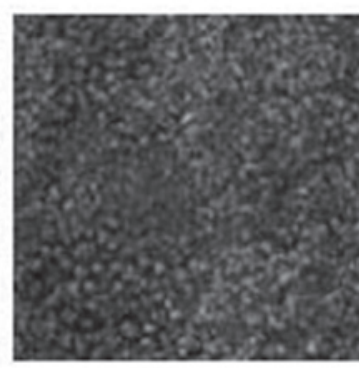

B

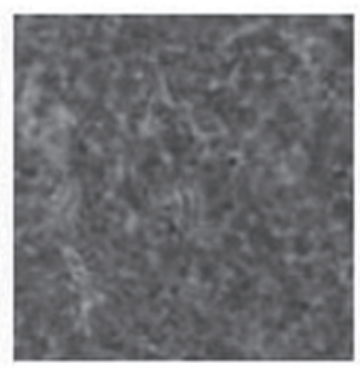

$\mathrm{C}$

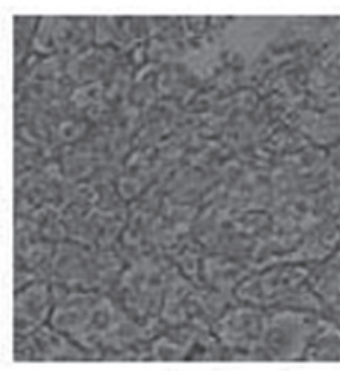

D

Control group (HE stain, $\times 400)$

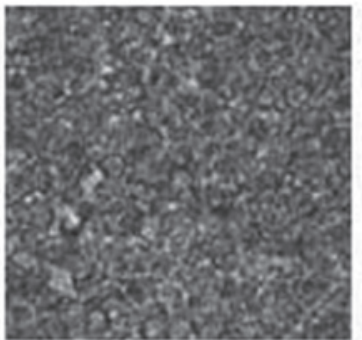

B

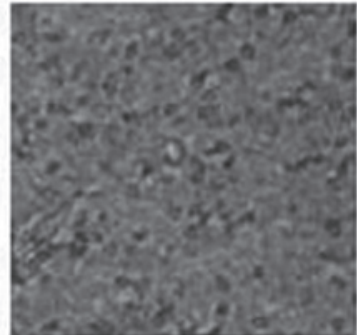

$\mathrm{C}$

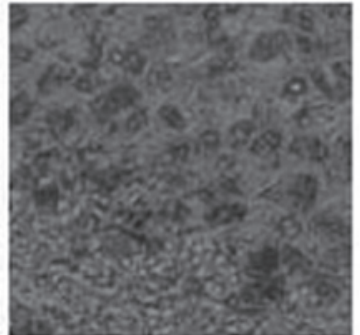

D

\section{RPS23 group (HE stain, $\times 400$ )}

Figure 7. Histological preparations of (A) the liver, (B) spleen, (C) thymus and (D) tumor in the RPS23-treated group (concentration, $0.1 \mu \mathrm{g} / \mathrm{ml}$ ) compared with the control group.

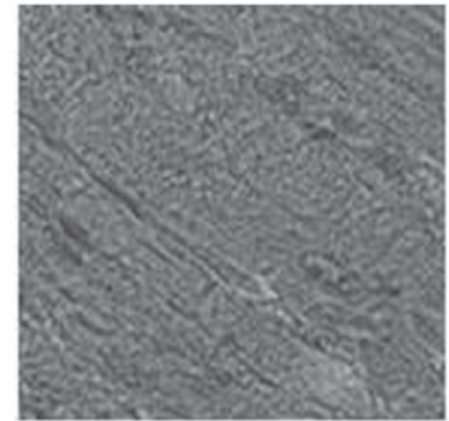

A

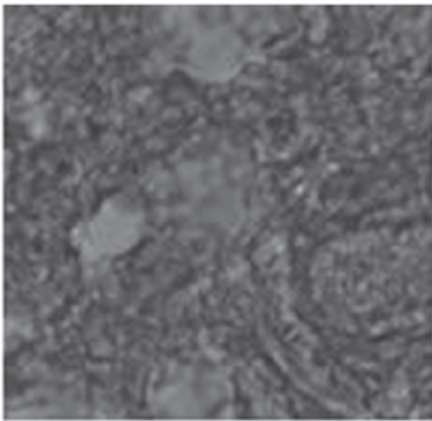

B

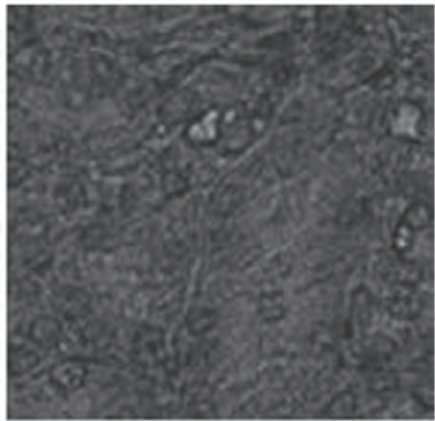

C

Control group (HE stain, $\times 400)$

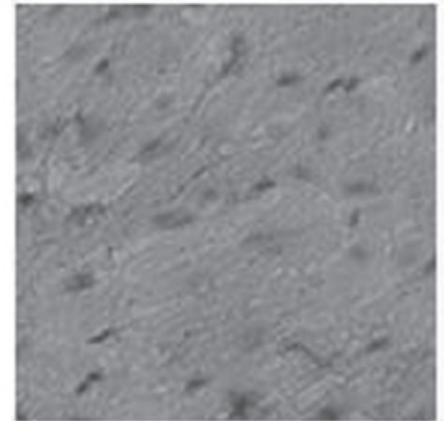

A

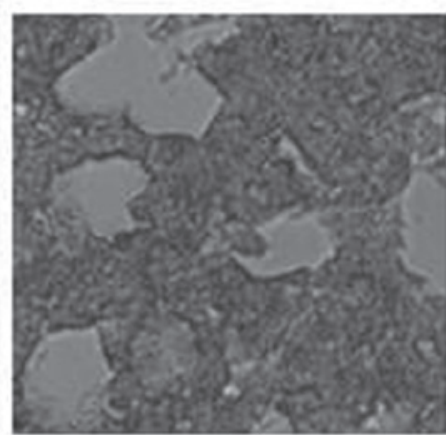

B

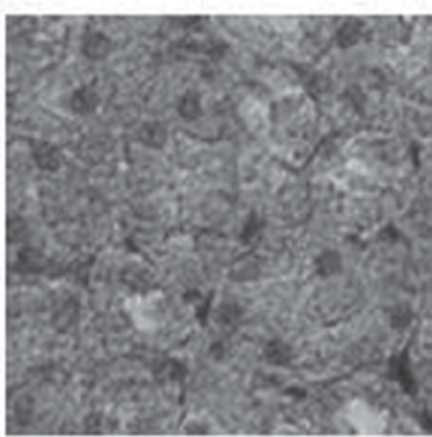

C

RPS23 group (H E stain, $\times 400)$

Figure 8. Histological preparations of (A) the heart, (B) lung and (C) kidney in the RPS23-treated group (concentration, $0.1 \mu \mathrm{g} / \mathrm{ml}$ ) compared with the control group. 
protein RPS23 fusion with the N-terminal His-tag form triggered the accumulation of an expected $21.5-\mathrm{kDa}$ polypeptide that formed inclusion bodies. The recombinant protein was expressed after half an hour of induction and after $3 \mathrm{~h}$ reached the highest level. The expression product obtained could be used for purification and further investigation of its function. Under the optimized expression conditions, a number of recombinant proteins were obtained, which were then purified using Ni-NTA chelate affinity chromatography. Protein separation and purification are key steps in genetic engineering technology. Consequently, purified protein was obtained through affinity chromatography. During affinity chromatography, the $\mathrm{pH}$ of the protein solution was altered twice which enabled us to achieve a highly purified protein. Particularly, the protein solution initially went through the column under acid conditions, and then finally outflowed from the column by changing the $\mathrm{pH}$ of the effluent liquid. SDS-PAGE analysis clearly indicated that there were $\sim 21.5-\mathrm{kDa}$ polypeptides in the lanes 3-5 with a theoretical pI of 10.57 (Fig. 6). Size consistency of the purified and unpurified RPS23 protein suggest that this is the only protein encoded by the RPS 23 gene from the giant panda.

Antitumor activity of RPS23 in vivo. The antitumor activity of RPS23 in vivo was subsequently examined. Mice transplanted with S180 were used to investigate the effects of RPS23 in vivo (Table I). The weight and histological preparations of vital organs in each male mouse of the control group were compared to those in the mice of the RPS23-treated group. RPS23 was found to inhibit the growth of the tumors $(\mathrm{P}<0.01)$ in a dose-dependent manner (Table III). The inhibitory rate of tumor growth in mice treated with $0.1 \mu \mathrm{g} / \mathrm{ml}$ RPS23 was $49.45 \%$, which was the highest in the three doses used. Furthermore, during the experiments, the appetite, activity and coat luster of each animal in the RPS23-treated groups were improved compared with the mice treated with mannatide. Histology of immune organs including liver, spleen and thymus showed that tissues were characterized by regular and tight arrangement, while the tumor tissue of the mice in the RPS23-treated group exhibited a loose arrangement compared with the control group. No obvious damage to other organs, such as the heart, lung and kidney was evident (Figs. 7 and 8). The results also indicated a slight change in the average liver weight in the mice of the test groups, showing that RPS23 did not cause serious liver damage (Table III). On the 14th day, the average tumor weight of negative control mice was $1.52 \mathrm{~g}$, while it was $0.77 \mathrm{~g}$ in the mice of the RPS23-treated group $(0.1 \mu \mathrm{g} / \mathrm{ml})$. The average tumor weight was also significantly reduced when doses of 0.05 and $0.025 \mu \mathrm{g} / \mathrm{ml}$ were used, resulting in 0.89 and $1.00 \mathrm{~g}$, respectively. Notably, the average weight of the spleens and thymus in the mice of the test groups was significantly increased when a dose of $0.05 \mu \mathrm{g}$ / $\mathrm{ml}$ was used compared with the negative control, and the mannatide-treated mice. These results indicated that RPS23 increased the weight of immune organs when moderate doses were used (Table III). Consequently, activation of immune responses in the host might constitute one of the mechanisms underlying the antitumor activity of RPS23. Studies on the mechanism and signal transduction pathways of RPS23 are currently being conducted.

\section{Acknowledgements}

This study was supported by the Application Foundation Project of Sichuan Province (no. 2011JY0135), the Foundation Project of Educational Committee of Sichuan Province (no. 10ZC120), the National Natural Science Foundation of China (no. 31200012) and the Doctor Startup Foundation Project of China West Normal University (nos. 11B019 and 11B020).

\section{References}

1. Wool IG: Extraribosomal functions of ribosomal proteins. Trends Biochem Sci 21: 164-165, 1996.

2. Wool IG, Chan YL and Glück A: Structure and evolution of mammalian ribosomal proteins. Biochem Cell Biol 73: 933-947, 1995.

3. Fan W, Christensen M, Eichler E, Zhang X and Lennon G: Cloning, sequencing, gene organization, and localization of the human ribosomal protein RPL23A gene. Genomics 46: 234-239, 1997.

4. Yang F and Liu WP: The progress of ribosomal protein genes and human diseases. J Clin Exp Pathol 20: 354-356, 2005.

5. Elantak L, Wagner S, Herrmannová A, Karásková M, Rutkai E, Lukavsky PJ and Valásek L: The indispensable N-terminal half of eIF3j/HCR1 cooperates with its structurally conserved binding partner eIF3b/PRT1-RRM and with eIF1A in stringent AUG selection. J Mol Biol 396: 1097-1116, 2010.

6. Unbehaun A, Marintchev A, Lomakin IB, Didenko T, Wagner G, Hellen CU and Pestova TV: Position of eukaryotic initiation factor eIF5B on the $80 \mathrm{~S}$ ribosome mapped by directed hydroxyl radical probing. EMBO J 26: 3109-3123, 2007.

7. Huang X, Chen Y, Li WB, Cohen SN, Liao FF, Li L, Xu H and Zhang YW: The Rps23rg gene family originated through retroposition of the ribosomal protein s 23 mRNA and encodes proteins that decrease Alzheimer's beta-amyloid level and tau phosphorylation. Hum Mol Genet 19: 3835-3843, 2010.

8. Anand P, Kunnumakkara AB, Sundaram C, Harikumar KB, Tharakan ST, Lai OS, Sung B and Aggarwal BB: Cancer is a preventable disease that requires major lifestyle changes. Pharm Res 25: 2097-2116, 2008.

9. Jemal A, Bray F, Center MM, Ferlay J, Ward E and Forman D: Global cancer statistics. CA Cancer J Clin 61: 69-90, 2011.

10. Tolar J and Neglia JP: Transplacental and other routes of cancer transmission between individuals. J Pediatr Hematol Oncol 25: 430-434, 2003.

11. Croce CM: Oncogenes and cancer. N Engl J Med 358: 502-511, 2008.

12. Wu GF, Hou YL, Hou WR, Song Y and Zhang T: Giant pandaribosomal protein s14: cDNA, genomic sequence cloning, sequence analysis, and overexpression. Genet Mol Res 9: 2004-2015, 2010.

13. Du YJ, Luo XY, Hao YZ, Zhang T and Hou WR: Cloning and overexpression of acidic ribosomal phosphoprotein P1 gene (RPLP1) from the giant panda. Inter J Biol Sci 3: 428-433, 2007.

14. Hou WR, Chen Y, Peng ZS, Wu X and Tang ZX: cDNA cloning and sequences analysis of ubiquinol-cytochrome $c$ reductase complex ubiquinone-binding protein (QP-C) from giant panda. Acta Theriol Sin 27: 190-194, 2007.

15. Hou YL, Du YJ, Hou WR, Zhou CQ, Hao YZ and Zhang T: Cloning and sequence analysis of translocase of inner mitochondrial membrane 10 homolog (yeast) gene (TIMM10) from the giant panda. J Cell Anim Biol 3: 9-14, 2009.

16. Liao MJ, Zhu MY, Zhang ZH, Zhang AJ, Li GH and Sheng FJ: Cloning and sequence analysis of FSH and LH in the giant panda (Ailuropoda melanoleuca). Anim Reprod Sci 77: 107-116, 2003.

17. Wu ZA, Liu WX, Murphy C and Gall J: Satellite 1 DNA sequence from genomic DNA of the giant panda Ailuropoda melanoleuca. Nucleic Acids Res 18: 1054, 1990. 